\title{
Corela
}

Cognition, représentation, langage

HS-30 | 2020

Phonétique, littérature et enseignement du FLE : théories et recherches

\section{Composition du comité de lecture du numéro}

\section{(2) OpenEdition}

Journals

Édition électronique

URL : http://journals.openedition.org/corela/10904

DOI : $10.4000 /$ corela. 10904

ISSN : 1638-573X

Éditeur

Cercle linguistique du Centre et de l'Ouest - CerLICO

Référence électronique

"Composition du comité de lecture du numéro », Corela [En ligne], HS-30 | 2020, mis en ligne le 14 mai 2020, consulté le 22 mai 2020. URL : http://journals.openedition.org/corela/10904 ; DOI : https:// doi.org/10.4000/corela.10904

Ce document a été généré automatiquement le 22 mai 2020.

\section{(c)}

Corela - cognition, représentation, langage est mis à disposition selon les termes de la licence Creative Commons Attribution - Pas d'Utilisation Commerciale - Partage dans les Mêmes Conditions 4.0 International. 


\section{Composition du comité de lecture du numéro}

Ont été sollicités pour évaluer les articles de ce numéro :

2 Dominique ABRY (Université Grenoble-Alpes, France)

3 Florentina FREDET (Université Sorbonne Nouvelle-Paris 3, France)

4 Enrica GaLAzzi (Université catholique de Milan, Italie)

5 Bertrand LAURET (Université Sorbonne Nouvelle-Paris 3, France)

6 Régine LloRca (Université de Franche-Comté, CLA, France)

7 Grégory MIRAs (Université de Rouen Normandie, France)

8 Chiara MOLINARI (Università degli Studi di Milano, Italie)

9 Christos NiKou (responsable du comité de lecture, Sorbonne Université - Faculté des Lettres, CRLC/EA 4510, France)

10 Claire PILLOT-LOISEAU (Université Sorbonne Nouvelle-Paris 3, France)

11 Julie VELDEMAN-ABRY (Université catholique de Lyon, ILCF, France)

12 Sandrine wachs (Université Sorbonne Nouvelle-Paris 3, France)

13 Corinne WEBER (Université Sorbonne Nouvelle-Paris 3, France) 